\title{
Magnetically filtered Faraday probe for measuring the ion current density profile of a Hall thruster
}

\author{
Joshua L. Rovey, ${ }^{\text {a) }}$ Mitchell L. R. Walker, and Alec D. Gallimore \\ Plasmadynamics and Electric Propulsion Laboratory, Department of Aerospace Engineering, \\ College of Engineering, The University of Michigan, Ann Arbor, Michigan 48109 \\ Peter Y. Peterson \\ QSS Inc., NASA Glenn Research Center, Cleveland, Ohio 44135
}

(Received 17 June 2005; accepted 10 November 2005; published online 12 January 2006)

\begin{abstract}
The ability of a magnetically filtered Faraday probe (MFFP) to obtain the ion current density profile of a Hall thruster is investigated. The MFFP is designed to eliminate the collection of low-energy, charge-exchange (CEX) ions by using a variable magnetic field as an ion filter. In this study, a MFFP, Faraday probe with a reduced acceptance angle (BFP), and nude Faraday probe are used to measure the ion current density profile of a $5 \mathrm{~kW}$ Hall thruster operating over the range of $300-500 \mathrm{~V}$ and $5-10 \mathrm{mg} / \mathrm{s}$. The probes are evaluated on a xenon propellant Hall thruster in the University of Michigan Large Vacuum Test Facility at operating pressures within the range of $4.4 \times 10^{-4} \mathrm{~Pa} \mathrm{Xe}\left(3.3 \times 10^{-6}\right.$ Torr Xe) to $1.1 \times 10^{-3} \mathrm{~Pa} \mathrm{Xe}\left(8.4 \times 10^{-6}\right.$ Torr Xe) in order to study the ability of the Faraday probe designs to filter out CEX ions. Detailed examination of the results shows that the nude probe measures a greater ion current density profile than both the MFFP and BFP over the range of angular positions investigated for each operating condition. The differences between the current density profiles obtained by each probe are attributed to the ion filtering systems employed. Analysis of the results shows that the MFFP, operating at a +5 A solenoid current, provides the best agreement with flight-test data and across operating pressures. () 2006 American Institute of Physics. [DOI: 10.1063/1.2149006]
\end{abstract}

\section{INTRODUCTION}

A Hall-effect thruster (HET) is a coaxial device that utilizes a radial magnetic field crossed with an axial electric field. Electrons emitted by the cathode drift in the $\mathbf{E} \times \mathbf{B}$ direction, forming an azimuthal Hall current. Neutral xenon atoms injected through the anode collide with these electrons producing xenon ions that are subsequently accelerated by the electric field to produce thrust. A mixture of electrons and ions in the acceleration zone creates a quasineutral plasma and thus the operation of the HET is not space-charge limited in ion current density as in the case of gridded ion thrusters. A schematic of a HET is shown in Fig. 1.

Several numerical codes have been developed to determine the impact of a HET plume on a spacecraft. ${ }^{1-3}$ Inputs for the codes are typically the ion energy and ion current density distributions. These distributions are usually obtained as a function of the angle with respect to the thruster centerline. Ion current density distributions are usually obtained using "nude" Faraday probes. A nude Faraday probe is an ion collector that uses no ion filtering schemes and is shown in Fig. 2. Due to facility effects, nude Faraday probe results collected in different facilities can be significantly different depending on the facility geometry and background pressure. ${ }^{4}$ This makes the comparison of current density profiles taken in different facilities, which inevitably have dif-

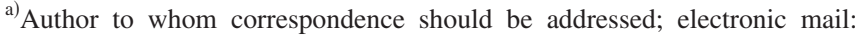
jrovey@umich.edu
}

ferent pumping speeds and background pressures, questionable. Therefore, the University of Michigan has launched an investigation that seeks to understand facility effects introduced by elevated backpressures more fundamentally. This investigation has included the characterization of the performance of the P5 HET at different pumping speeds, ${ }^{5}$ an evaluation of a collimated Faraday probe to filter out chargeexchange (CEX) ions while measuring the ion current density at elevated backpressures, ${ }^{6}$ characterization of the Large Vacuum Test Facility (LVTF) backpressure during thruster cold-flow and hot-flow operations, ${ }^{7-9}$ the investigation of plasma properties near a nude Faraday probe during HET plume characterization, ${ }^{10}$ and analyzing facility effects on the performance and plume of a HET cluster. ${ }^{11}$

At elevated backpressure, facility effects are primarily driven by resonant CEX collisions in which a "fast" plume ion exchanges an electron with a "slow" background neutral. The result of this process is a slow positively charged ion and a fast neutral. A nude Faraday probe is incapable of distinguishing between slow CEX ions and fast plume ions and thus both contribute to the measured current. There are also many CEX ions created at or near the thruster exit plane and subsequently accelerated to significant velocity. Although it is possible that low-energy, CEX ions are produced by the thruster, these ions are expected to be less than $1 \%$ of the plume. Ions that comprise the thruster plume need to be included in any numerical sputtering model. It is only desirable to obtain the ion current density profile that would be present if CEX collisions between plume ions and the facility 


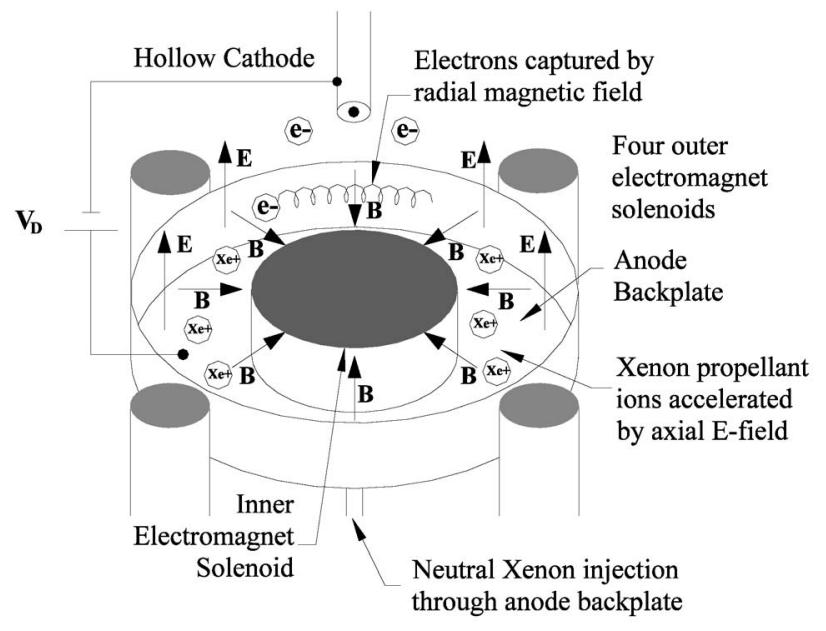

FIG. 1. Schematic of a Hall-effect thruster.

background gas were not present, i.e., the true ion current density profile. de Grys et al., suggest that CEX ions due primarily to facility effects have energies less than $20 \mathrm{eV} .^{12}$

Previous methods for obtaining the true ion current density profile have had varying degrees of success and have included using a second Faraday cup pointed away from the thruster, ${ }^{13}$ a retarding potential analyzer (RPA) to screen out CEX ions, ${ }^{14}$ a single-screen-gridded Faraday probe, ${ }^{15,16}$ and a biased collimator to filter CEX ions before they reach a
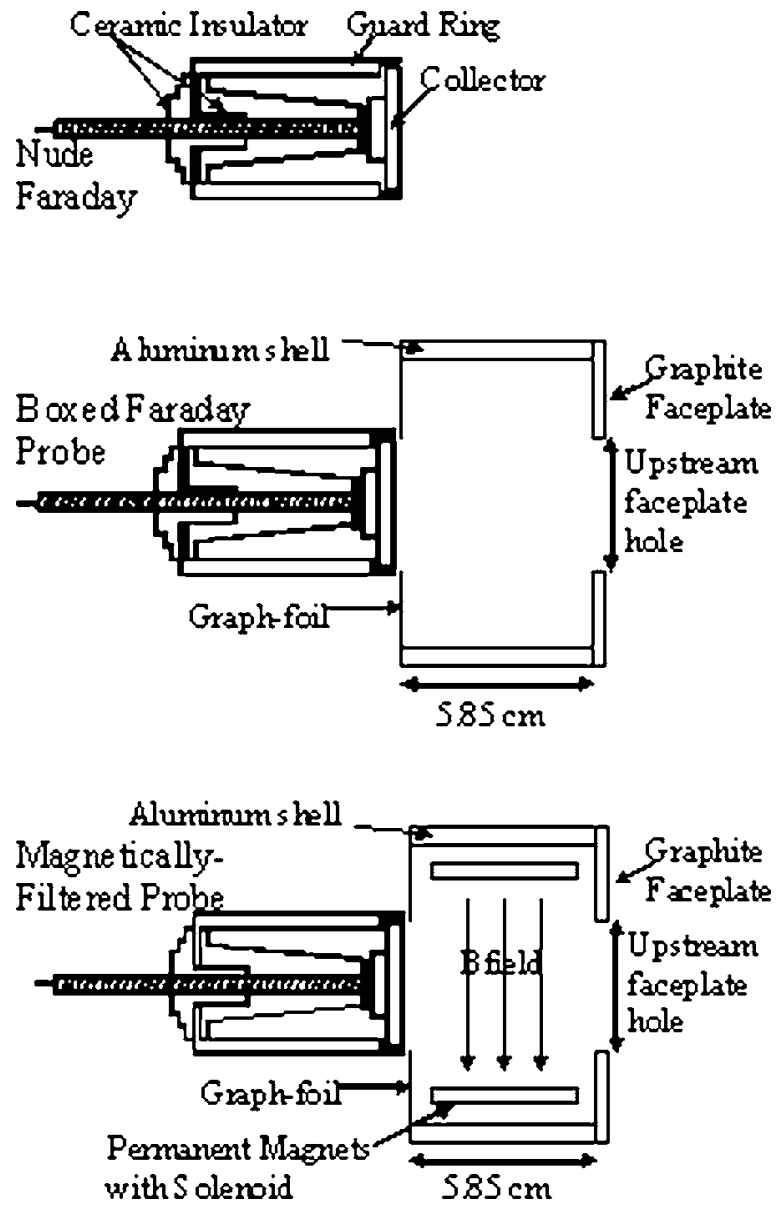

FIG. 2. Schematics of the nude Faraday probe, BFP, and MFFP. Not to scale.

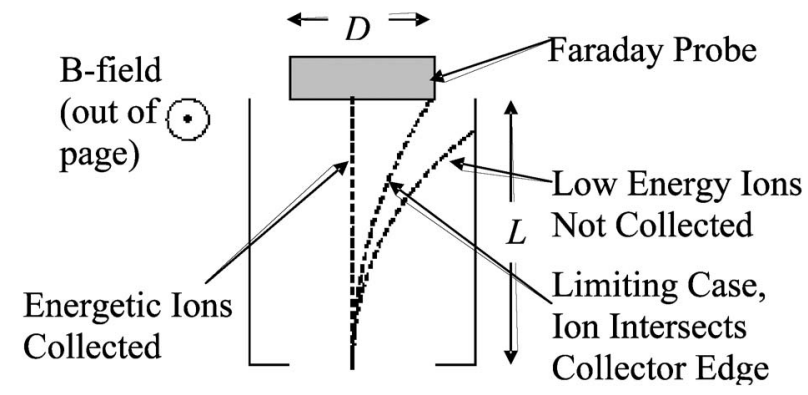

FIG. 3. First-order ion trajectory model for approximating the required distance and magnetic field to filter low-energy, CEX ions.

Faraday probe. ${ }^{6,12}$ Each of these techniques has its own advantages, but there is still another possible approach to obtaining the true ion current density profile. By utilizing a magnetic field, low-energy ions can effectively be turned so that their trajectories do not intersect the ion collecting surface. In this way the magnetic field acts as an ion filter, allowing only ions above a given energy threshold to be collected.

This paper investigates three types of Faraday probe plume diagnostics: a nude Faraday probe, a magnetically filtered Faraday probe (MFFP), and a "boxed" Faraday probe (BFP). Both the MFFP and BFP utilize ion filtration to eliminate the collection of facility induced CEX ions. By filtering CEX ions the ion current density profiles at different facility backpressures should be nearly identical. The purpose of this work is to aid in the development of plume characterization techniques for obtaining the true ion current density profile of a HET regardless of the facility background pressure. This paper briefly explains the shortcomings of nude Faraday probes, describes the diagnostics and experimental apparatus, presents the experimental data, and provides an explanation of the results.

\section{ION FILTRATION DEVICES}

\section{A. Magnetic filter}

Consider the setup shown in Fig. 3 where a magnetic field present over length $L$ is placed in front of a nude Faraday probe with diameter, $D$. The magnetic field is uniformly directed out of the page with flux density, $B$. An ion with energy, $E$, (or velocity, $\nu$ ) that enters on the probe centerline and travels toward the probe is turned by the perpendicular magnetic field. The ion follows an arc with radius equal to the Larmor radius defined by Eq. (1), ${ }^{17}$

$$
r_{L}=\frac{m \nu}{q B},
$$

where $m$ is the mass of the ion and $q$ is its charge. The energy of an ion entering on probe centerline whose trajectory intersects the outer edge of the collection surface is given by Eq. (2).

$$
E[e V]=\frac{q B^{2}}{2 m}\left(\frac{D}{4}+\frac{L^{2}}{D}\right)^{2} .
$$

The energy of the ions to be filtered is approximately $20 \mathrm{eV},{ }^{12}$ and the diameter of the probe collector is fixed at 


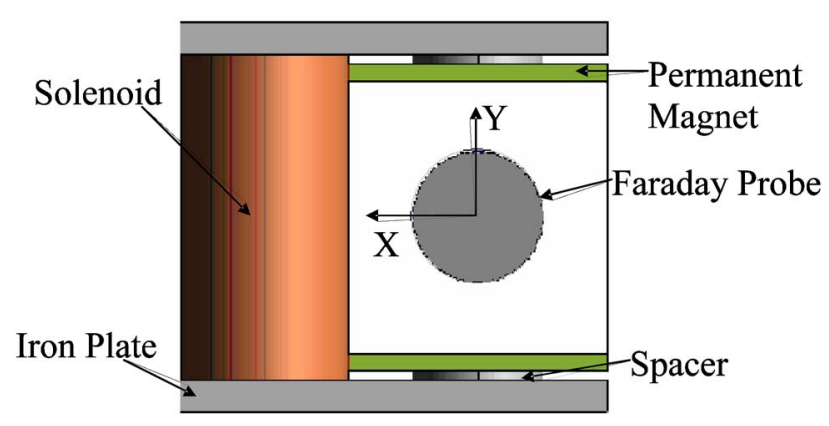

FIG. 4. (Color online) Solid model of the magnetic filter. Particles enter along the $z$ axis, directed into the page, and the magnetic field is along the $y$ axis.

$2.31 \mathrm{~cm}$. If we assume singly charged xenon ions, a relation between $B$ and $L$ can be determined. These results provide a baseline from which the magnetic-field design and modeling is initiated using the magnetostatic code MAGNET $6.0^{\mathrm{TM}}$.

The device in Fig. 4 is selected as the magnetic filter. Note that a nude Faraday probe is positioned behind the filter so that ions must first pass through the magnetic field before reaching the collector. The magnetic filter contains a cylindrical solenoid connected to two iron plates to form a "C" shape. Samarium cobalt permanent magnets are connected to the iron plates via a cylindrical iron spacer and are held in place by their own magnetic force. The magnets are required to increase the baseline magnetic flux density of the magnetic field and the spacers aid in turning the magnetic flux from the horizontal direction in the iron plates ( $x$ axis) to the required vertical direction ( $y$ axis). The solenoid can operate between $\pm 5 \mathrm{~A}$, with $+5 \mathrm{~A}$ increasing the flux density and -5 A reducing it. This yields a magnetic field with a flux density range of approximately $0.050-0.075 \mathrm{~T}$ in the center of the filter.

The line average of the magnetic field over an ion trajectory can be used in the trajectory model for ions entering along centerline described above. An estimation of the ion filtration range for centerline ions is approximately $8-30 \mathrm{eV}$ when the solenoid current is varied from -5 to $+5 \mathrm{~A}$. This is only an approximate range since off-centerline ions are also turned by the magnetic field and collected by the probe. Offcenterline ions can have energies as low as $15 \mathrm{eV}$ for the +5 A solenoid current.

A graphite faceplate is attached to the front of the filter and aluminum side panels are also attached. Both the faceplate and side panels are electrically grounded to the facility. The faceplate has a 2.54-cm- (1-in.)- diam hole machined directly upstream of the probe to allow ions to enter. The distance from the faceplate hole to the probe is $5.85 \mathrm{~cm}$. The side panels prevent stray ions from entering from the sides and being turned into the probe. In the back, the area between the probe and the filter is covered with graph-foil to prevent ions from entering from behind the filter and being collected by the probe. These measures attempt to ensure that ions only enter through the faceplate hole. Although pressure may increase inside the filter due to limited venting, a mass flow analysis of a similar device has shown this does not

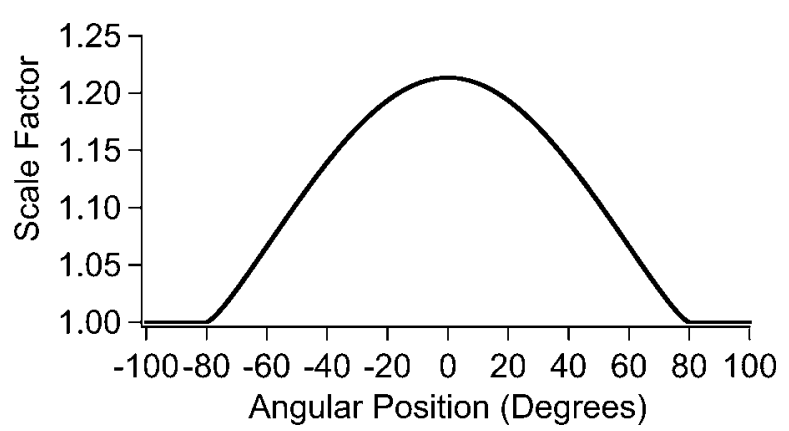

FIG. 5. Collimator scaling factor.

significantly affect probe performance. ${ }^{6}$ This setup is referred to as the MFFP and is shown in Fig. 2.

\section{B. Box}

It is important to note that the MFFP is essentially a collimated Faraday probe with a magnetic field inside the collimator. As such, there are two forms of ion filtration that are being utilized: a geometric collimator and a magnetic field. In order to analyze which filtration method is contributing most to changes in the measured ion current density, a BFP is also tested. The box does not contain a magnetic circuit and is shown in Fig. 2.

Both the MFFP and BFP utilize a geometric collimator as an ion filtration device, so collimated probe theory is required to compare those data sets with the nude Faraday probe. Collimated probe theory allows the comparison of data taken with a collimated and an uncollimated probe by utilizing a theoretical scaling factor based on the viewing angle (or geometry) of the probe. The scaling factor is the ratio between the ion current density that would be collected by an uncollimated probe divided by the current collected by a collimated probe. A detailed discussion of this theory is presented elsewhere ${ }^{6,12}$ and is not repeated here. For this work the scaling factor is calculated using the method outlined in Ref. 6. All data reported here for the MFFP and BFP have been multiplied by the scaling factor that is shown in Fig. 5.

\section{EXPERIMENTAL APPARATUS}

\section{A. Vacuum facility and Hall thruster}

The University of Michigan LVTF and the P5 Hall thruster, jointly developed by the University of Michigan and the Air Force Research Laboratory, are used for all the Faraday probe experiments. At high vacuum, the LVTF employs

TABLE I. LVTF background pressures for the various flowrates and pumping speeds investigated.

\begin{tabular}{ccccc}
\hline \hline $\begin{array}{c}\text { Nominal } \\
\text { pumping } \\
\text { speed }(1 / \mathrm{s})\end{array}$ & $\begin{array}{c}\text { Anode } \\
\text { flow } \\
(\mathrm{mg} / \mathrm{s})\end{array}$ & $\begin{array}{c}\text { Cathode } \\
\text { flow } \\
(\mathrm{mg} / \mathrm{s})\end{array}$ & $\begin{array}{c}\text { Pressure } \\
(\mathrm{Pa} \mathrm{Xe})\end{array}$ & $\begin{array}{c}\text { Pressure } \\
(\text { Torr Xe) }\end{array}$ \\
\hline 140000 & 5.25 & 0.92 & $7.5 E-04$ & $5.6 E-06$ \\
140000 & 10.46 & 0.92 & $1.1 E-03$ & $8.4 E-06$ \\
240000 & 5.25 & 0.92 & $4.4 E-04$ & $3.3 E-06$ \\
240000 & 10.46 & 0.92 & $6.7 E-04$ & $5.0 E-06$ \\
\hline \hline
\end{tabular}




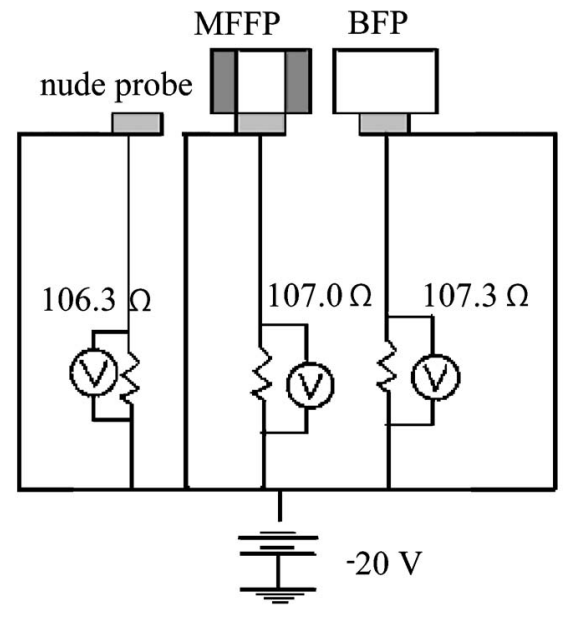

FIG. 6. Electrical setup of the nude probe, MFFP, and BFP.

seven CVI TM-1200 internal cryopumps that yield a facility pumping speed of $240000 \mathrm{l} / \mathrm{s}$ on xenon with a base pressure of $3.3 \times 10^{-5} \mathrm{~Pa}\left(2.5 \times 10^{-7}\right.$ Torr $)$. The chamber pressure is monitored using both an internal and external hot-cathode ionization gauge. Pressure measurements from the gauges are corrected for xenon using the known base pressure on air and a correction factor of 2.87 for xenon according to the following equation: ${ }^{18}$

$$
P_{c}=\frac{P_{i}-P_{b}}{2.87}+P_{b},
$$

where $P_{c}$ is the corrected pressure on xenon, $P_{b}$ is the base pressure, and $P_{i}$ is the indicated pressure when xenon is flowing into the vacuum chamber. Corrected pressure for the nude ion gauge is reported as the background pressure in the chamber. A recent investigation of the pressure field inside the LVTF during HET cold-flow operation has shown that the nude gauge provides better agreement with the true pressure of the facility. 8,9

The P5 is a laboratory-model Hall thruster with a nominal power rating of $5 \mathrm{~kW}$. A more detailed description of the P5 can be found in Ref. 19. A lanthanum hexaboride $\left(\mathrm{LaB}_{6}\right)$ laboratory-model hollow cathode is located at the 2 o'clock position on the thruster. The cathode orifice is located approximately $30 \mathrm{~mm}$ downstream and $25 \mathrm{~mm}$ radially away from the outer front pole piece. Table I shows the operating pressures for the LVTF using four and seven cryopumps with the different P5 anode flowrates.

\section{B. Faraday probe}

The MFFP, BFP, and nude Faraday probe are simultaneously investigated. The Faraday probes used for the MFFP and BFP are identical to the nude Faraday probe, Fig. 2. Each probe has a $2.31 \mathrm{~cm}(0.91 \mathrm{in}$.) diameter collection electrode enclosed within a guard ring. A spray coating of tungsten over the aluminum collector helps to minimize secondary-electron emission. In order to create a flat, uniform sheath over the collection electrode, both the collector and guard ring are biased to the same potential below facility ground as shown in Fig. 6.

\section{Data-acquisition system}

The probes are attached to a rotating arm, positioned $100 \mathrm{~cm}$ downstream of the thruster, and aligned with the center of the P5 exit plane. The angular coordinate system for data presentation is such that the thruster centerline is considered $0^{\circ}$, and facing downstream from the thruster exit plane and rotating counterclockwise is considered the positive direction. With the MFFP positioned on centerline the BFP and nude Faraday probe are located at $-14.85^{\circ}$ and $29.8^{\circ}$, respectively.

A data logger measures the voltage drop across three current shunts as shown in Fig. 6. The ion current density is calculated by dividing the measured voltage by the known probe area and the shunt resistance. Measurements from all three probes are taken in $1^{\circ}$ increments.

\section{EXPERIMENTAL RESULTS}

All reported data are taken with the collector and guard ring of all the Faraday probes biased to $-20 \mathrm{~V}$ below ground. Table II presents the investigated thruster operating conditions. The thruster is operated at discharge voltages of 300 and $500 \mathrm{~V}$ with discharge currents of 5 and $10 \mathrm{~A}$, at background pressures within the range of $4.4 \times 10^{-4} \mathrm{~Pa} \mathrm{Xe}(3.3$ $\times 10^{-6}$ Torr $\left.\mathrm{Xe}\right)$ to $1.1 \times 10^{-3} \mathrm{~Pa} \mathrm{Xe}\left(8.4 \times 10^{-6}\right.$ Torr $\left.\mathrm{Xe}\right)$ on xenon.

Figures 7 and 8 show typical ion current density profiles for the nude probe, MFFP, and BFP at the operating condi-

TABLE II. P5 operating conditions.

\begin{tabular}{|c|c|c|c|c|c|c|c|c|c|}
\hline $\begin{array}{c}\text { No. } \\
\text { of } \\
\text { Pumps }\end{array}$ & $V_{d}(\mathrm{~V})$ & $I_{d}(\mathrm{~A})$ & $\begin{array}{c}\text { Anode } \\
\text { flow } \\
(\mathrm{mg} / \mathrm{s})\end{array}$ & $\begin{array}{c}\text { Cathode } \\
\text { flow } \\
(\mathrm{mg} / \mathrm{s})\end{array}$ & $I_{i c}(\mathrm{~A})$ & $I_{o c}(\mathrm{~A})$ & $V_{c-g}(\mathrm{~V})$ & $\begin{array}{c}\text { Pressure } \\
(\mathrm{Pa} \mathrm{Xe})\end{array}$ & $\begin{array}{c}\text { Probe } \\
\text { bias wrt } \\
\text { Grd } \\
\text { (V) }\end{array}$ \\
\hline 4 & 300 & 4.80 & 5.25 & 0.92 & 2.25 & 1.08 & -17.3 & $7.5 E-04$ & -20 \\
\hline 4 & 300 & 9.78 & 10.46 & 0.92 & 4.00 & 2.00 & -23.3 & $1.1 E-03$ & -20 \\
\hline 4 & 500 & 5.38 & 5.25 & 0.92 & 3.52 & 1.51 & -15.8 & $7.5 E-04$ & -20 \\
\hline 4 & 500 & 9.80 & 10.46 & 0.92 & 5.00 & 2.01 & -27.4 & $1.1 E-03$ & -20 \\
\hline 7 & 300 & 4.78 & 5.25 & 0.92 & 2.22 & 1.05 & -16.4 & $4.4 E-04$ & -20 \\
\hline 7 & 300 & 9.44 & 10.46 & 0.92 & 4.00 & 2.00 & -20.3 & $6.7 E-04$ & -20 \\
\hline 7 & 500 & 5.18 & 5.25 & 0.92 & 3.52 & 1.50 & -16.6 & $4.4 E-04$ & -20 \\
\hline 7 & 500 & 9.52 & 10.46 & 0.92 & 5.01 & 2.00 & -21.3 & $6.7 E-04$ & -20 \\
\hline
\end{tabular}




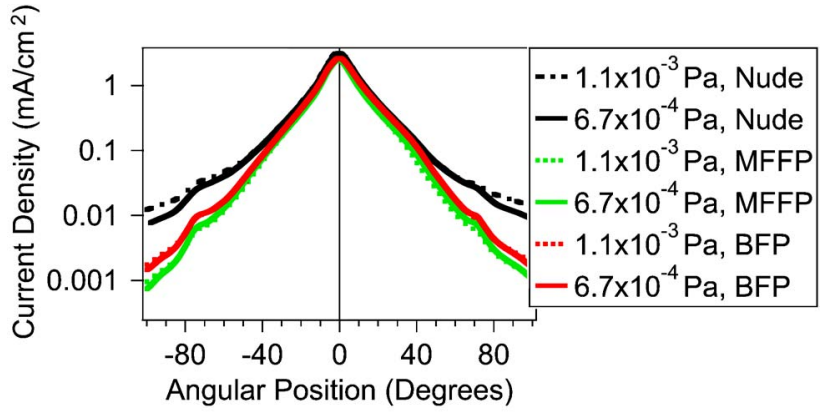

FIG. 7. (Color online) Ion current density versus position for the nude probe, MFFP (+5 A), and BFP at facility pressures of $1.1 \times 10^{-3}$ and $6.7 \times 10^{-4} \mathrm{~Pa}$ Xe. (Thruster operating at $500 \mathrm{~V}, 9.80 \mathrm{~A}$, and $9.52 \mathrm{~A}$, respectively.)

tions investigated. The nude probe, BFP, and MFFP measure similar plume profiles, and similar trends are seen in all the current density profiles at all thruster operating conditions. The nude probe consistently measures a larger current density at each angular position, a trend that becomes increasingly noticeable farther from centerline.

On centerline the nude probe measures current densities that are on average 17\% and 32\% larger than the BFP and MFFP (+5 A solenoid current), respectively. At a -5 A solenoid current, the MFFP measures approximately the same centerline current density as the BFP. When the MFFP is operated at $+5 \mathrm{~A}$ it measures a current density $11 \%$ less than the BFP. When operated at 0 A the MFFP still has a magnetic field due to the permanent magnets and therefore measures a smaller centerline current density than the BFP.

Figure 9 shows the effect of changing the solenoid current on the measured current density profile at off-centerline angular positions. Similar results are obtained at all thruster operating conditions. The BFP consistently measures a larger current density than the MFFP, regardless of the solenoid current and facility pressure. For the MFFP, increasing the solenoid current causes a decrease in the measured current density. The differences become increasingly apparent as the angular position from the centerline increases. Changing the facility pressure has little effect on these trends. Because all other parameters are identical, the differences between the current density profiles obtained by each probe must be due to the ion filtering systems employed.

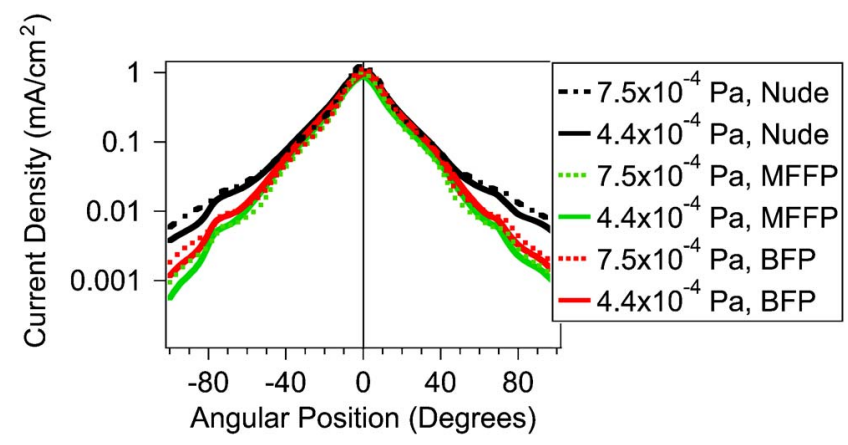

FIG. 8. (Color online) Ion current density versus position for the nude probe, MFFP $(+5 \mathrm{~A})$, and BFP at facility pressures of $7.5 \times 10^{-4}$ and $4.4 \times 10^{-4} \mathrm{~Pa} \mathrm{Xe}$. (Thruster operating at $300 \mathrm{~V}, 4.80 \mathrm{~A}$, and $4.78 \mathrm{~A}$, respectively.)

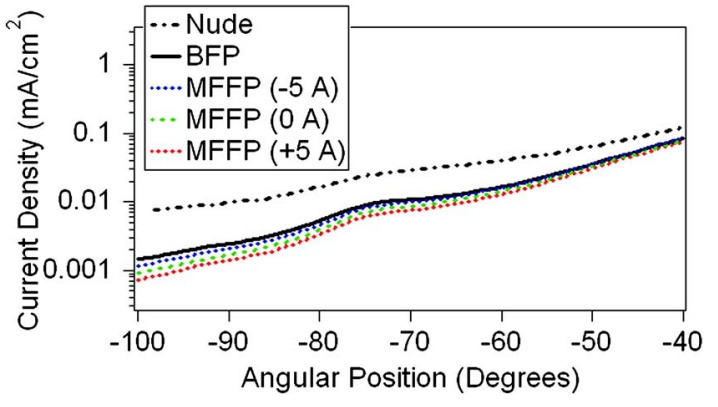

FIG. 9. (Color online) Comparison of off-centerline current density profiles for the nude probe, BFP, and MFFP. Operating conditions are $500 \mathrm{~V}, 9.80 \mathrm{~A}$ at a facility pressure of $1.1 \times 10^{-3} \mathrm{~Pa} \mathrm{Xe}$.

\section{DISCUSSION}

Four main sources of measurement uncertainty are present during data collection. Uncertainty associated with measurements of the current shunt voltage drop, shunt resistance, axial probe location, and probe collector diameter are approximately $\pm 0.005 \%, \pm 0.5 \%, \pm 0.05 \%$, and $\pm 1 \%$, respectively. Error associated with the hardware used in this study is published by the manufacturer and user measurement uncertainty is estimated based on repeatability. Utilizing these values the uncertainties for the current density, total ion current, and plume divergence angle are estimated as $\pm 2.5 \%$, $\pm 6.4 \%$, and $\pm 5.0 \%$, respectively.

Figure 10 is a plot of the integrated ion beam current versus the facility background pressure. Integrated ion beam current is calculated using Eq. (4), ${ }^{4}$

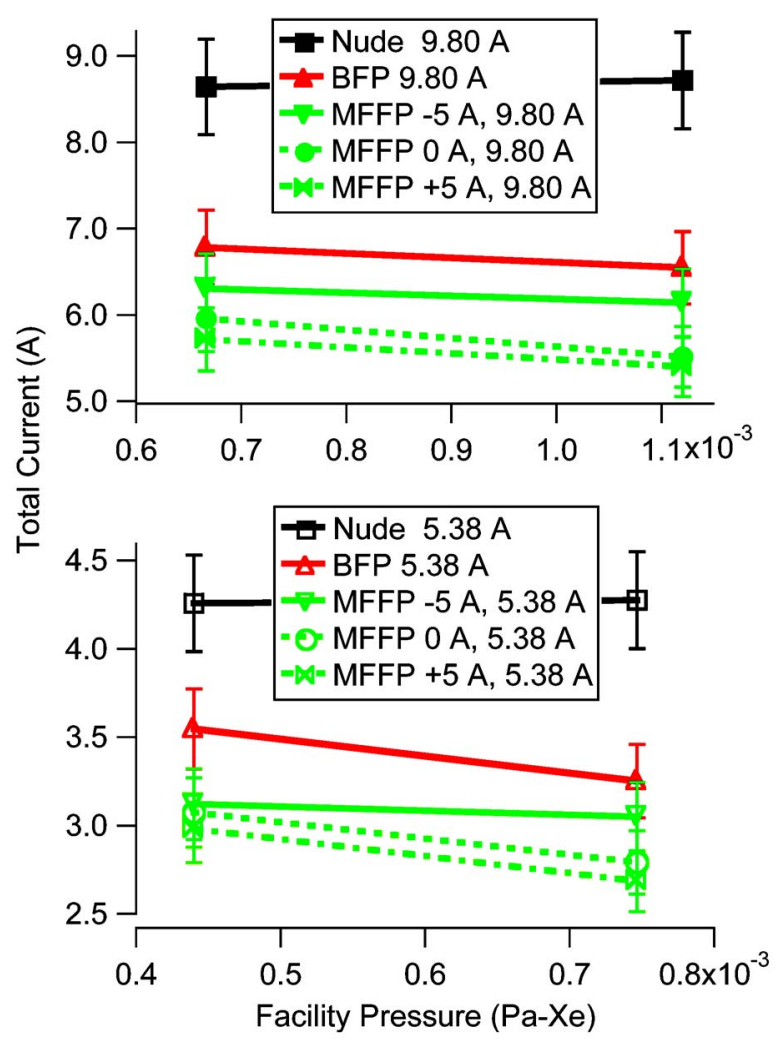

FIG. 10. (Color online) Integrated ion beam current as a function of facility pressure for the nude probe, BFP, and MFFP. Thruster operating conditions are $500 \mathrm{~V}$ and 5.38 or $9.80 \mathrm{~A}$. 


$$
I_{\mathrm{tot}}=2 \pi z^{2} \int_{0}^{\pi / 2} j_{z}(\theta) \sin \theta d \theta,
$$

where $z$ is the probe distance from the thruster and $j_{z}(\theta)$ is the ion current density measured at the angular position, $\theta$. Due to the asymmetry of the current density profile, the reported integrated ion beam current is the average of the integrated ion beam current calculated using only the positive side and the integrated ion beam current calculated using only the negative side of the current density profile. Increasing the facility pressure causes the integrated ion beam current measured by the nude probe to increase, but for the BFP and MFFP the integrated ion beam current decreases with increasing pressure. The nude probe integrated ion beam current increases an average of $1 \%$ when the facility pressure increases, however, this result is within the measurement uncertainty. Integrated ion beam current measurements for the BFP show an average decrease of $5 \%$ as the facility pressure increases. At $-5,0$, and +5 A the MFFP integrated ion beam current decreases an average of $3 \%, 6 \%$, and $6 \%$, respectively. As we will show later, this result is explained by the ion beam attenuation due to CEX collisions at elevated background pressures.

Figure 11 examines the changes in the $90 \%$ plume divergence half-angle, which is defined as the half-angle encompassing $90 \%$ of the beam current, as a function of the facility pressure. Divergence half-angles calculated using the BFP and MFFP consistently decrease as the facility pressure increases. The nude probe does not display the same trend for each thruster operating condition. Higher facility pressure causes an increase in the divergence half-angle for the $500 \mathrm{~V}, 5 \mathrm{~A}$ case, but a decrease in half-angle for the $300 \mathrm{~V}$, 5 A condition. It should be noted that these results are within the measurement uncertainty and similar results for nude probes have also been reported by Walker et al. ${ }^{20}$

Haas considered a biased Faraday probe as a point source potential sink for slow, CEX ions. ${ }^{21}$ However, recent results by Walker et al., do not show a substantial electric field near an operational nude Faraday probe. ${ }^{10}$ The lack of a strong, local electric field suggests that CEX ions are collected because of their random, thermal motion and not because of the negative probe bias. Mikellides has shown that
TABLE III. Beam attenuation due to CEX collisions over a $100 \mathrm{~cm}$ path length.

\begin{tabular}{ccc}
\hline \hline Operating condition & $\begin{array}{c}\text { Pressure } \\
(\mathrm{Pa} \mathrm{Xe})\end{array}$ & $\begin{array}{c}\text { Attenuation } \\
(\%)\end{array}$ \\
\hline $5 \mathrm{~A}: 300 \mathrm{~V}, 500 \mathrm{~V}$ & $4.4 E-04$ & 6 \\
$5 \mathrm{~A}: 300 \mathrm{~V}, 500 \mathrm{~V}$ & $7.5 E-04$ & 9 \\
$10 \mathrm{~A}: 300 \mathrm{~V}, 500 \mathrm{~V}$ & $6.7 E-04$ & 8 \\
$10 \mathrm{~A}: 300 \mathrm{~V}, 500 \mathrm{~V}$ & $1.1 E-03$ & 14 \\
\hline \hline
\end{tabular}

elastically scattered ions with significant energy $(\sim 150 \mathrm{eV}$ for a $300 \mathrm{~V}$ discharge) are also an appreciable component of the Hall thruster plume at large angles and nude probes tend to collect more of these ions than collimated probes. ${ }^{22}$

As the plume expands, ions necessarily have collisions with neutral particles that are present due to diffusion from the thruster discharge channel, but also due to the background pressure of the facility. At a higher facility pressure fewer beam ions traverse the distance to the probe without suffering a CEX or elastic collision. A first-order estimation of the beam attenuation due to CEX collisions is obtained by considering the ion continuity equation in one dimension. At the energies investigated, the elastic collision cross section is an order of magnitude smaller than the CEX cross section, so only CEX ions are considered. ${ }^{23,24}$ The ratio of the ion current density at some downstream position to the initial ion current density is obtained by integrating over the path length $z$. The result is Eq. (5), ${ }^{25}$

$$
\frac{j_{z}(\theta)}{j(\theta)}=\exp \left(-n_{b} \sigma_{c e} z\right)
$$

where $j_{z}(\theta)$ is the ion current density at downstream position $z$ and angular position $\theta, j(\theta)$ is the initial ion current density at position $\theta, n_{b}$ is the neutral background number density, and $\sigma_{c e}$ is the CEX collision cross section. Facility-induced CEX ions are most noticeable at large off-axis angles where the pressure is approximately equal to the facility background pressure. Therefore, the neutral background number density is based on the facility background pressure. The beam attenuation for the pressures investigated is given in Table III. These calculations are evaluated at $100 \mathrm{~cm}$ down-

TABLE IV. Comparison of the integrated ion beam current and corrected integrated ion beam current percent

\begin{tabular}{|c|c|c|c|c|c|c|c|c|}
\hline & \multicolumn{4}{|c|}{$\begin{array}{c}\text { Four Pumps }(7.5 E-04 \mathrm{~Pa}) \text { to } \\
\text { seven Pumps }(4.4 E-04 \mathrm{~Pa})\end{array}$} & \multicolumn{4}{|c|}{$\begin{array}{c}\text { Four Pumps }(1.1 E-03 \mathrm{~Pa}) \text { to } \\
\text { seven Pumps }(6.7 E-04 \mathrm{~Pa})\end{array}$} \\
\hline & $\begin{array}{l}300 \mathrm{~V} \\
I_{\text {tot }} \\
\text { Percent } \\
\text { diff. } \\
(\%)\end{array}$ & $\begin{array}{c}5 \mathrm{~A} \\
I_{\text {tot }, c} \\
\text { Percent } \\
\text { diff. } \\
(\%)\end{array}$ & $\begin{array}{c}500 \mathrm{~V} \\
I_{\text {tot }} \\
\text { Percent } \\
\text { diff. } \\
(\%)\end{array}$ & $\begin{array}{c}5 \mathrm{~A} \\
I_{\text {tot, } c} \\
\text { Percent } \\
\text { diff. } \\
(\%)\end{array}$ & $\begin{array}{l}300 \mathrm{~V} \\
I_{\text {tot }} \\
\text { Percent } \\
\text { diff. } \\
(\%)\end{array}$ & $\begin{array}{c}10 \mathrm{~A} \\
I_{\text {tot }, c} \\
\text { Percent } \\
\text { diff. } \\
(\%)\end{array}$ & $\begin{array}{l}500 \mathrm{~V} \\
I_{\text {tot }} \\
\text { Percent } \\
\text { diff. } \\
(\%)\end{array}$ & $\begin{array}{c}10 \mathrm{~A} \\
I_{\mathrm{tot}, c} \\
\text { Percent } \\
\text { diff. } \\
(\%)\end{array}$ \\
\hline Nude & 0.4 & 3.6 & 0.4 & 3.6 & 2.0 & 8.4 & 0.8 & 7.3 \\
\hline $\mathrm{BFP}$ & -4.7 & -1.3 & -9.0 & -5.6 & -3.0 & 3.7 & -3.6 & 3.2 \\
\hline $\operatorname{MFFP}(-5 \mathrm{~A})$ & -3.1 & 0.2 & -2.3 & 0.9 & -2.8 & 3.9 & -2.7 & 4.0 \\
\hline $\operatorname{MFFP}(0 \mathrm{~A})$ & -3.3 & 0.0 & -10.1 & -6.6 & -4.3 & 2.5 & -8.0 & 3.1 \\
\hline $\operatorname{MFFP}(+5 \mathrm{~A})$ & -3.8 & -0.4 & -11.0 & -7.4 & -4.7 & 2.2 & -6.0 & 1.0 \\
\hline
\end{tabular}
difference between the four and seven pump data. 


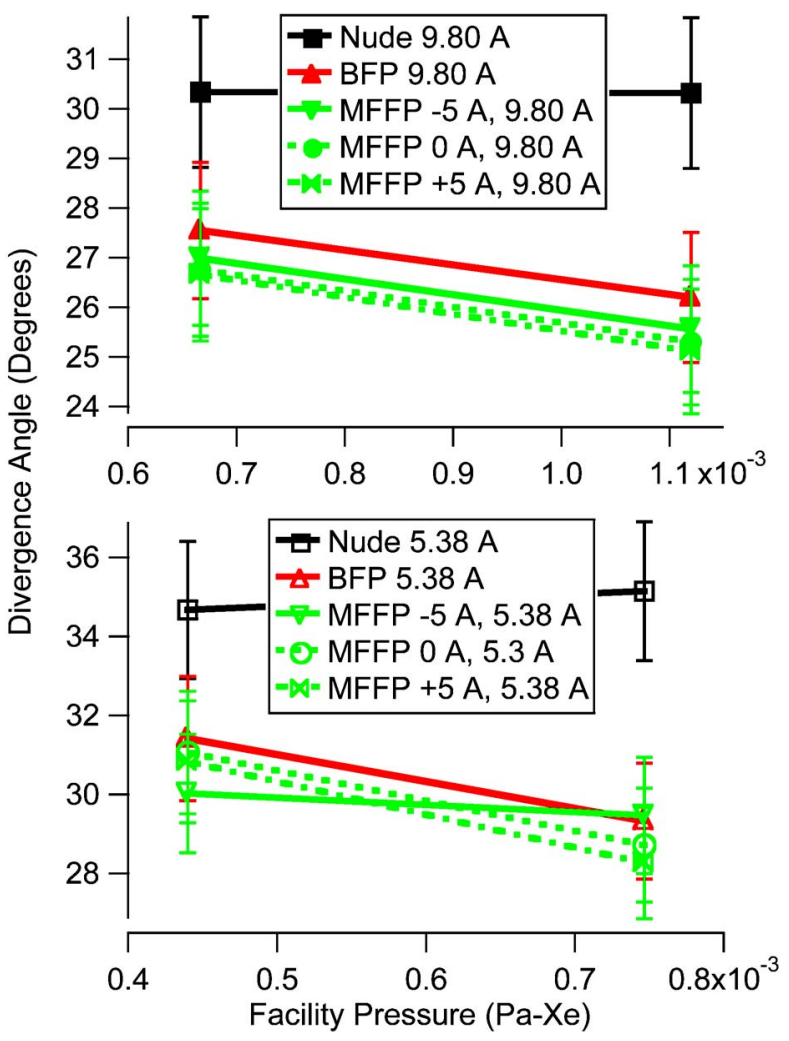

FIG. 11. (Color online) Plume divergence angle as a function of facility pressure for the nude probe, BFP, and MFFP. Thruster operating conditions are $500 \mathrm{~V}$ and 5.38 or $9.80 \mathrm{~A}$.

stream of the thruster and assume a neutral temperature of $300 \mathrm{~K}$ and a CEX collision cross section of $51 \AA^{2,23}$ These values provide an estimation of the beam attenuation.

At the $5 \mathrm{~A}$ operating condition the beam attenuation decreases from $9 \%$ to $6 \%$ when going from four to seven pumps $\left(7.5 \times 10^{-5}-4.4 \times 10^{-4} \mathrm{~Pa} \mathrm{Xe}\right)$. The corresponding change at $10 \mathrm{~A}$ is $14 \%$ to $8 \%$. In order to account for beam attenuation, the corrected integrated ion beam current is calculated by using Eq. (5) with the initial ion current density. This allows the integrated ion beam current, $I_{\text {tot }}$, to be compared with the corrected integrated ion beam current, $I_{\mathrm{tot}, c}$. Table IV shows this comparison where a positive percent difference means the four pump integrated beam current is larger than the seven pump value.

All of the thruster operating conditions except for the $500 \mathrm{~V}, 5 \mathrm{~A}$ condition show the largest percent difference is obtained by the nude probe, followed by the BFP, and then the MFFP. When the thruster is operated at $500 \mathrm{~V}, 5 \mathrm{~A}$ the

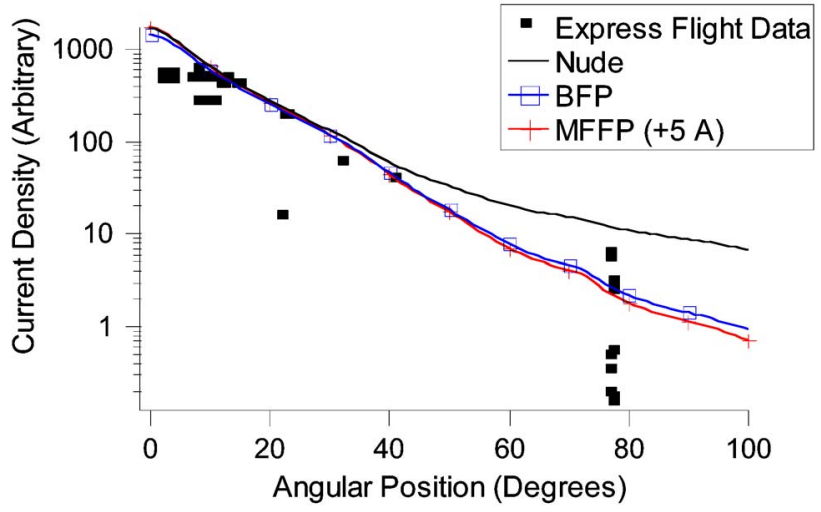

FIG. 12. (Color online) Comparison of Express satellite on-orbit data from Ref. 26 with the nude probe, BFP, and MFFP.

BFP, MFFP (0 A), and MFFP (+5 A) record a larger percent difference for both $I_{\text {tot }}$ and $I_{\text {tot }, c}$. An explanation for this difference has not yet been determined. Based on the three other operating conditions, the MFFP at +5 A shows the best corrected integrated ion beam current agreement across facility pressures.

The current density profiles associated with the MFFP are also more consistent with data obtained from space. Figure 12 compares the nude probe, BFP, and MFFP normalized current density profiles with the Russian Express satellite data. ${ }^{26}$ This figure indicates there is considerable spread in the Express data, which can vary as much as an order of magnitude for the same angular location. It is not the aim of this work to agree exactly with the data, but rather to examine trends. Current density data obtained on-orbit do not exhibit the increased current densities at off-axis angles as often seen in nude probe ground test data. ${ }^{26}$ Compared to the nude probe and BFP, the MFFP provides a profile more consistent with flight test data because it measures a lower current density at angles off centerline and shows the characteristic $r^{-2}$ dependence.

The ability of each probe to obtain the correct ion beam current is analyzed by comparing the corrected integrated ion beam current to discharge current ratio with the P5 current utilization efficiency. The current utilization efficiency, $\eta_{b}$, is defined as the ratio of the ion beam current to the discharge current, $I_{b} / I_{d}$. An estimation of the current utilization efficiency for the P5 can be obtained by considering the following equation for the anode efficiency

$$
\eta_{a}=\eta_{b} \eta_{v} \eta_{q} \eta_{m}
$$

where $\eta_{a}$ is the anode efficiency, $\eta_{q}$ is the charge utilization efficiency, $\eta_{m}$ is the mass utilization efficiency, and $\eta_{v}$ is the

TABLE V. Approximation of the P5 current utilization efficiency based on the charge, mass, voltage, and anode efficiencies.

\begin{tabular}{|c|c|c|c|c|c|}
\hline $\begin{array}{l}\text { Operating } \\
\text { condition }\end{array}$ & $\begin{array}{c}\text { Anode } \\
\text { efficiency }\end{array}$ & $\begin{array}{c}\text { Voltage } \\
\text { utilization } \\
\text { efficiency }\end{array}$ & $\begin{array}{l}\text { Charge } \\
\text { utilization } \\
\text { efficiency }\end{array}$ & $\begin{array}{c}\text { Mass } \\
\text { utilization } \\
\text { efficiency }\end{array}$ & $\begin{array}{c}\text { Current } \\
\text { utilization } \\
\text { Efficiency }\end{array}$ \\
\hline $300 \mathrm{~V}, 5 \mathrm{~A}$ & 0.47 & 0.90 & 0.98 & 0.76 & 0.70 \\
\hline $500 \mathrm{~V}, 5 \mathrm{~A}$ & 0.50 & 0.90 & 0.96 & 0.72 & 0.80 \\
\hline $500 \mathrm{~V}, 10 \mathrm{~A}$ & 0.56 & 0.90 & 0.99 & 0.88 & 0.72 \\
\hline
\end{tabular}


TABLE VI. Comparison of $I_{\mathrm{tot}, c} / I_{d}$ for the nude probe, BFP, and MFFP and the estimated $I_{b} / I_{d}$ for the P5 at the investigated operating conditions.

\begin{tabular}{|c|c|c|c|c|c|c|c|c|c|}
\hline $\begin{array}{c}\text { Pressure } \\
(\mathrm{Pa} \mathrm{Xe})\end{array}$ & $\begin{array}{c}\text { No. } \\
\text { of } \\
\text { Pumps }\end{array}$ & $\begin{array}{c}V_{d} \\
(\mathrm{~V})\end{array}$ & $\begin{array}{c}I_{d} \\
(\mathrm{~A})\end{array}$ & $\begin{array}{c}\text { Nude } \\
\text { probe } \\
I_{\text {tot, }, c} / I_{d}\end{array}$ & $\begin{array}{c}\mathrm{BFP} \\
I_{\mathrm{tot}, c} / I_{d}\end{array}$ & $\begin{array}{l}\text { MFFP } \\
(-5 \mathrm{~A}) \\
I_{\mathrm{tot}, c} / I_{d}\end{array}$ & $\begin{array}{c}\text { MFFP } \\
(0 \mathrm{~A}) \\
I_{\mathrm{tot}, c} / I_{d}\end{array}$ & $\begin{array}{l}\text { MFFP } \\
(+5 \mathrm{~A}) \\
I_{\mathrm{tot}, c} / I_{d}\end{array}$ & $\begin{array}{l}\text { Estimated } \\
\text { P5 } I_{b} / I_{d}\end{array}$ \\
\hline $7.5 E-04$ & 4 & 300 & 4.80 & 0.94 & 0.72 & 0.66 & 0.59 & 0.56 & 0.70 \\
\hline $7.5 E-04$ & 4 & 500 & 5.38 & 0.87 & 0.66 & 0.62 & 0.57 & 0.55 & 0.80 \\
\hline $1.1 E-03$ & 4 & 500 & 9.80 & 1.03 & 0.78 & 0.73 & 0.65 & 0.64 & 0.72 \\
\hline $4.4 E-04$ & 7 & 300 & 4.78 & 0.91 & 0.73 & 0.66 & 0.60 & 0.57 & 0.70 \\
\hline $4.4 E-04$ & 7 & 500 & 5.18 & 0.87 & 0.73 & 0.64 & 0.63 & 0.61 & 0.80 \\
\hline $6.7 E-04$ & 7 & 500 & 9.52 & 0.99 & 0.77 & 0.72 & 0.68 & 0.65 & 0.72 \\
\hline
\end{tabular}

voltage utilization efficiency. ${ }^{27}$ In order to determine the current utilization efficiency, values for the other four efficiencies must be obtained. The P5 anode efficiency has been reported by Hofer. ${ }^{27}$ Gulczinski has reported ion energy data for the P5 that suggest the voltage utilization efficiency is approximately $90 \%{ }^{28}$ The charge utilization efficiency and mass utilization efficiency are calculated using far-field ion species fraction data provided by Gulczinski ${ }^{28}$ and the Hall thruster performance model for a multiply charged plasma recently developed by Hofer. ${ }^{27}$ Unfortunately, ion species fraction data are not available for the $300 \mathrm{~V}, 10 \mathrm{~A}$ operating condition. So no current utilization data are provided at this condition. The results are summarized in Table V.

Ideally, a Faraday probe should have an integrated ion beam current to discharge current ratio equal to the current utilization efficiency. Comparison of the calculated current utilization efficiency for the P5 and the $I_{\text {tot, } c} / I_{d}$ for each probe is shown in Table VI. The nude probe performs worst and consistently overpredicts the ion beam current. Depending on the operating condition, either the BFP or MFFP provides the best agreement with the estimated current utilization efficiency. It should be noted that the reported P5 current utilization efficiency is an estimation based on data taken a few years prior to the current investigation. It is possible that the P5 thruster is presently performing with a lower current utilization than the older data predict. Furthermore, it has been noted in other investigations that the operational characteristics of a Hall thruster change with facility pressure. ${ }^{11}$

\section{ACKNOWLEDGMENTS}

The authors would like to thank Dr. Colleen Marrese at JPL for loaning PEPL the nude Faraday probes, Dr. Sergi Khartov at MAI for the use of the $\mathrm{LaB}_{6}$ cathode, Mr. Terry Larrow for fabricating the hardware used in this study, undergraduates M. Baldwin, C. Berkley, R. Livingston, S. Shepard, and J. Topper for assembly and preliminary testing of the MFFP, Torsten Stindl of the Universität Stuttgart for help with experimental setup and data acquisition, and the departmental technical staff and other graduate students at
PEPL for help in maintaining the facilities. This research was supported by the Air Force Office of Scientific Research through Grants Nos. F49620-00-1-0201 and F49620-01-10061. In addition, graduate support was provided by the Michigan Space Grant Consortium and the National Science Foundation. The authors greatly appreciate this support.

${ }^{1}$ J. M. Fife et al., AIAA Paper No. AIAA-2000-3521 (2000) (unpublished).

${ }^{2}$ I. D. Boyd and A. Ketsdever, J. Spacecr. Rockets 38, 380 (2001).

${ }^{3}$ I. D. Boyd, J. Spacecr. Rockets 38, 381 (2001).

${ }^{4}$ D. H. Manzella, AIAA Paper No. AIAA-95-2927 (1995) (unpublished).

${ }^{5}$ R. R. Hofer, P. Y. Peterson, and A. D. Gallimore, AIAA Paper No. IEPC01-045 (2001) (unpublished).

${ }^{6}$ R. R. Hofer, M. L. R. Walker, and A. D. Gallimore, AIAA Paper No. IEPC-01-020 (2001) (unpublished).

${ }^{7}$ M. L. R. Walker and A. D. Gallimore, AIAA Paper No. IEPC-03-0077 (2003) (unpublished).

${ }^{8}$ M. L. R. Walker, J. Propul. Power 20, 1127 (2004).

${ }^{9}$ M. L. R. Walker and A. D. Gallimore, Rev. Sci. Instrum. 76, 053509 (2005).

${ }^{10}$ M. L. R. Walker, A. L. Victor, R. R. Hofer, and A. D. Gallimore, J. Propul. Power 21, 408 (2005).

${ }^{11}$ M. L. R. Walker, Ph.D. thesis, University of Michigan, 2005.

${ }^{12}$ K. H. de Grys, D. L. Tilley, and R. S. Aadland, AIAA Paper No. AIAA99-2283 (1999) (unpublished).

${ }^{13}$ L. B. King, A. D. Gallimore, and C. M. Marrese, J. Propul. Power 14, 327 (1998).

${ }^{14}$ V. Kim, AIAA Paper No. AIAA-98-3787 (1998) (unpublished).

${ }^{15}$ B. E. Beal, Ph.D. thesis, University of Michigan, 2004.

${ }^{16}$ P. Y. Peterson, Ph.D. thesis, University of Michigan, 2004.

${ }^{17}$ F. F. Chen, Introduction to Plasma Physics and Controlled Fusion, Plasma Physics, Vol. 1 (Plenum, New York, 1984).

${ }^{18}$ S. Dushman, Scientific Foundations of Vacuum Technique, (Wiley, New York, 1958) Vol. 4.

${ }^{19}$ J. M. Haas et al., AIAA Paper No. AIAA-98-3503 (1998) (unpublished).

${ }^{20}$ M. L. R. Walker, R. R. Hofer, and A. D. Gallimore, AIAA Paper No. AIAA-2002-4253 (2002) (unpublished).

${ }^{21}$ J. M. Haas, Ph.D. thesis, University of Michigan, 2001.

${ }^{22}$ I. Mikellides, I. Katz, R. A. Kuharski, and M. J. Mandell, J. Propul. Power 21, 111 (2005).

${ }^{23}$ J. S. Miller et al., J. Appl. Phys. 91, 984 (2002).

${ }^{24}$ I. D. Boyd and R. A. Dressler, J. Appl. Phys. 92, 1764 (2002).

${ }^{25}$ J. S. Sovey and M. J. Patterson, AIAA Paper No. AIAA-91-2117 (1991) (unpublished).

${ }^{26}$ D. H. Manzella et al., AIAA Paper No. IEPC-01-44 (2001) (unpublished).

${ }^{27}$ R. R. Hofer, Ph.D. thesis, University of Michigan, 2004.

${ }^{28}$ F. S. Gulczinski, Ph.D. thesis, University of Michigan, 1999. 